\title{
Torsion of the Wandering Spleen and Pancreatic Tail Precipitating Diabetic Ketoacidosis in a Patient with Prader Willi Syndrome: A Case Report
}

\author{
Loh Wann Jia, ${ }^{1}$ Chan Weng Hoong, ${ }^{2}$ Tham Kwang Wei ${ }^{1}$ \\ ${ }^{1}$ Department of Endocrinology, Singapore General Hospital \\ ${ }^{2}$ Department of General Surgery, Singapore General Hospital
}

\begin{abstract}
Prader Willi Syndrome (PWS) includes complex endocrinological issues because of the hypothalamic and pituitary dysfunction which include obesity and diabetes, as well as behavioural issues. Other important aspects of PWS, such as hepatosplenomegaly are sometimes neglected. We present a case of diabetic ketoacidosis precipitated by torsion of a wandering spleen in a 22-year-old woman with PWS and type 2 diabetes mellitus. The pancreatic tail was involved in the torsion leading to hyperamylasaemia and pancreatitis. The splenic torsion and pancreatitis were initially treated conservatively with resolution of symptoms. A year later, she had another 2 episodes of severe abdominal pain due to worsening splenic torsion which subsided with conservative management. She subsequently underwent an elective splenectomy which revealed an enlarged and wandering spleen, with 720 degrees torsion of the long splenic pedicle.
\end{abstract}

Key words: Prader-Willi syndrome, spleen torsion, wandering spleen and diabetic ketoacidosis

\section{INTRODUCTION}

Prader-Willi syndrome (PWS) is a genetic disorder due to lack of expression of genes on the paternally inherited chromosome 15q11.2-q13. The prevalence of PWS is about 1 in 25,000 live births. ${ }^{1}$ The endocrine issues associated with PWS are extensive because of the hypothalamic and pituitary dysfunction which includes obesity, diabetes, adrenal insufficiency, growth hormone deficiency and hypothyroidism. Type 2 diabetes mellitus (T2DM) occurs in $25 \%$ of adults with PWS with mean onset age of 20 years, and a mean BMI of $27 \mathrm{~kg} / \mathrm{m}^{2} .2,3$

In the early stages of diabetic ketoacidosis (DKA), the cause of abdominal pain can be difficult to establish. Routine computed tomography (CT) scan for every DKA would lead to over-investigation. This is because diffuse abdominal pain occurs in more than $50 \%$ of patients with $\mathrm{DKA}^{4}$ and resolves with appropriate DKA treatment. However, a persistent abdominal pain warrants further investigation. Wandering spleen is a rare disorder due to absence or weakness of the ligaments holding the spleen in the normal position. We present an interesting case of torsion of wandering spleen in a PWS patient. A search of PUBMED and other search engines were done and to our knowledge, this has not been reported in literature before.

eISSN 2308-118x

Printed in the Philippines

Copyright $(2016$ by the JAFES

Received: October 7, 2015. Accepted: January 30, 2016.

http://dx.doi.org/10.15605/jafes.031.01.08

\section{CASE}

A 22-year-old Chinese female, with a known history of PWS and T2DM presented to the emergency room with fever (Tmax $40.2^{\circ} \mathrm{C}$ ), and 3-day history of sore throat, dry cough and coryza. She also had diffuse abdominal pain, diarrhea and decreased appetite for 3 days. During this period, her father noticed she had increased thirst with polyuria. On the day of admission, she was weak and breathless. There was no dysuria, weight loss or chest pain. Further history revealed that she was not compliant with her oral diabetic medications since her mother passed away a year ago.

At birth, she was cyanotic and hypotonic. In her infancy, she had difficulty feeding and required temporary nasogastric tube feeding. Around the age of 4-5 years old, she had increased appetite. This progressed to hyperphagia and obesity a few years later. She had delayed language, milestones, delayed motor development and reduced intellectual abilities. At age 18, she had impaired fasting glucose and was started on metformin. A year later, she was diagnosed with mild T2DM that was well-controlled with $\mathrm{HbA1c}$ of $5.9-6.3 \%$ on metformin. Her mother passed away from cancer a year ago and she became non-compliant with her food intake

Corresponding author: Loh Wann Jia, MBBS, BSC(Hons), MRCP

Endocrine Registrar

Department of Endocrinology, Singapore General Hospital,

Academia, 20, College Road, Singapore 169856

Tel. No.: +65-65767858

Fax No.: +65 63266042

E-mail: loh.wann.jia@singhealth.com.sg 
and reduced her exercise. Eight months ago, her $\mathrm{HbA} 1 \mathrm{c}$ deteriorated to $12.4 \%$ and she gained $5 \mathrm{~kg}$. Her diabetic medications were changed to extended-release Metformin $1500 \mathrm{mg}$ daily and Gliclazide modified-release $60 \mathrm{mg}$ daily. Her other medical issues included dyslipidaemia and primary hypothyroidism from Hashimoto's thyroiditis, non-alcoholic fatty liver disease and irregular menses since puberty at 13 years old.

There was no significant family history of diabetes or PWS. Her father and paternal grandmother had hyperlipidaemia. This hospital admission was 10 months after her mother's death. Her height was $1.46 \mathrm{~m}$ and weight $64 \mathrm{~kg}$, BMI $30 \mathrm{~kg} / \mathrm{m}^{2}$. She had typical facial features of Prader-Willi syndrome with rounded faces, narrow bifrontal diameter, almond-shaped eyes, small mouth with thin upper lip, small hands and feet.

On admission, she was hypotensive (BP of 85/41 mm Hg), tachycardic (heart rate $140 \mathrm{bpm}$ ), tachypneic (respiratory rate 34 breaths per min) with a pulse oxygen saturation (SpO2) of $99 \%$ at $2 \mathrm{~L} \mathrm{O} 2 / \mathrm{min}$ and febrile at $38.6^{\circ} \mathrm{C}$. She was lethargic but was able to recognise her family members. She was severely dehydrated with dry mucous membrane and haemodynamic instability. She had generalised abdominal pain and a large palpable mass in the left upper quadrant (splenomegaly). Her lungs were clear on auscultation.

Capillary blood glucose was "High." Urine dipstick was positive with glucose and 3+ ketones. Venous blood gas confirmed metabolic acidosis (Table 1). She was diagnosed with DKA and treated with prompt hydration and intravenous insulin infusion. She received 3 litres of normal saline within the first 2 hours which resulted in normalisation of her blood pressure and heart rate. She received another 3 litres of intravenous fluids over the next 24 hours. She was given an initial intravenous bolus dose of 0.1 unit $/ \mathrm{kg}$ of regular insulin followed by 0.1 unit/kg/hour of insulin. The insulin rate was subsequently titrated according to the capillary glucose. Antibiotics were initiated for suspected sepsis but further tests showed that there was no evidence of sepsis. Insulin autoantibodies of anti-islet cell and GAD were negative.

At the point of examination, her abdominal pain had improved and therefore the decision was to monitor her symptoms. Overnight, the ketonaemia resolved and capillary glucose was subsequently maintained at 6.3-11.3 $\mathrm{mmol} / \mathrm{L}$ the following day (Figure 1).

Despite resolution of DKA, she continued to have intermittent diffuse abdominal pain. Her abdomen was soft on examination. Although abdominal pain is common in DKA, the recurrence of her pain was suspicious for underlying abdominal pathology. Serum amylase and lipase were elevated at $358 \mathrm{U} / \mathrm{L}$ (38-149) and $>600$ units respectively. Her haemoglobin and platelets dropped. An urgent CT scan of the abdomen and pelvis was performed

\begin{tabular}{|c|c|c|}
\hline Test & Patient's Result & Reference Range \\
\hline \multicolumn{3}{|l|}{ Full blood count } \\
\hline Haemoglobin & 13.5 & $12-16 \mathrm{~g} / \mathrm{dl}$ \\
\hline Total white cell count & 12.15 & $4-10 \times 10(9) / L$ \\
\hline Neutrophil count & 9.24 with left shift & $2-7.5 \times 10(9) / \mathrm{L}$ \\
\hline Platelet count & 208 & $140-440 \times 10(9) / \mathrm{L}$ \\
\hline \multicolumn{3}{|l|}{ Biochemistry } \\
\hline Sodium & 148 & $136-146 \mathrm{mmol} / \mathrm{L}$ \\
\hline Potassium & 5 & $3.6-5 \mathrm{mmol} / \mathrm{L}$ \\
\hline Chloride & 107 & $100-107 \mathrm{mmol} / \mathrm{L}$ \\
\hline Bicarbonate & 7.6 & $19.0-29.0 \mathrm{mmol} / \mathrm{L}$ \\
\hline Glucose & 51.6 & $3.9-11 \mathrm{mmolL}$ \\
\hline Urea & 23.6 & $2.7-6.9 \mathrm{mmol} / \mathrm{l}$ \\
\hline Creatinine & 118 & $37-75 \mathrm{umol} / \mathrm{l}$ \\
\hline Corrected Calcium & 2.18 & $2.09-2.46 \mathrm{mmol} / \mathrm{l}$ \\
\hline Phosphate & 0.72 & $0.94-1.5 \mathrm{mmol} / \mathrm{l}$ \\
\hline Serum ketones & $>6$ & $0.0-0.6 \mathrm{mmol} / \mathrm{L}$ \\
\hline \multicolumn{3}{|l|}{ Liver function } \\
\hline Total protein & 56 & $68-86 \mathrm{~g} / \mathrm{L}$ \\
\hline Albumin & 30 & $40-51 \mathrm{~g} / \mathrm{L}$ \\
\hline Bilirubin & 5 & $7-32 \mathrm{umol} / \mathrm{L}$ \\
\hline Alkaline Phosphatase & 105 & $39-99 \mathrm{U} / \mathrm{L}$ \\
\hline ALT & 36 & $6-66 \mathrm{U} / \mathrm{L}$ \\
\hline AST & 137 & $1-42 \mathrm{U} / \mathrm{L}$ \\
\hline \multicolumn{3}{|l|}{ Thyroid function test } \\
\hline Free T4 & 10.3 & $8.8-14.4 \mathrm{pmol} / \mathrm{L}$ \\
\hline TSH & 1.19 & $0.65-3.7 \mathrm{mU} / \mathrm{L}$ \\
\hline \multicolumn{3}{|l|}{ Venous Blood Gas } \\
\hline $\mathrm{pH}$ & 7.305 & \\
\hline Base Excess & -13.4 & $\mathrm{mmol} / \mathrm{l}$ \\
\hline pCO2 & 32 & $\mathrm{mmHg}$ \\
\hline
\end{tabular}

and showed torsion of the enlarged spleen involving the pancreatic tail with moderate amount of free fluid in the abdomen. The splenic torsion caused the anaemia, thrombocytopenia ${ }^{5}$ and pancreatitis. The underlying reason for the spontaneous splenic torsion was a wandering spleen.

The wandering spleen is due to absence of ligaments to hold the spleen in its normal anatomical position and thus at high risk of splenic torsion, infarction and rupture. ${ }^{6}$ An urgent surgical opinion was requested as splenic torsion usually requires splenectomy. Serial abdominal examination found that her abdominal pain was improving, and she was haemodynamically stable and thus, the decision was made for conservative management.

The major cause of DKA in this patient with PWS was precipitated by splenic torsion with acute pancreatitis. Her lifestyle changes and poor compliance to medication also contributed to her worsening diabetic control. Her HbA1c this admission was $13.1 \%$ which reflected a poor glucose control for the past 3 months. This was not surprising as her mother's absence caused emotional breakdown leading to uncontrolled hyperphagia and excessive weight gain. She was discharged well.

\section{Outcome and Follow up}

A year later, she had another 2 episodes of severe abdominal pain due to worsening splenic torsion which subsided with conservative management. Initially the patient's father was not agreeable for an elective 
splenectomy; however he subsequently changed his mind in view of the repeated abdominal pain attacks. She underwent an elective splenectomy which found a wandering enlarged spleen with long splenic pedicle that had torsion of 720 degrees. Prior to the splenectomy, she received Haemophilus type B, Pneumococcal and Meningococcal vaccinations. She was given aspirin for post-splenectomy thrombocytosis.

\section{DISCUSSION}

Patients with PWS have increased mortality rate which is mainly due to obesity-related diseases. ${ }^{7}$ Thus, a review by Emerick and Vogt recommended that screening for diabetes, hyperlipidaemia and hepatic steatosis in PWS be done in similar way as for an obese patient. ${ }^{2}$ Diabetic ketoacidosis (DKA) in T2DM is increasingly seen, with about $30 \%$ in United States ${ }^{8}$ whereas $50-64 \%$ of DKA patients are made up of T2DM in China. ${ }^{9-10}$ DKA can occur in T2DM with PWS, ${ }^{11}$ but is rarely reported in literature.

The pathophysiology of DKA is the same in PWS and non-PWS. It occurs in absolute or relative deficiency of insulin with excess counter-regulatory hormones causing hyperglycaemia and exaggerated lipolysis with ketone production. Glucotoxicity from chronic hyperglycaemia and lipotoxicity from chronically raised plasma free fatty acids in obesity impair insulin action and secretion. ${ }^{12}$ The recovery phase of the beta cell function requires resolution of glucotoxicity and lipotoxicity, with possibility of weaning off insulin. Treatment of the factors that precipitated the DKA is important, and in this case, a splenic torsion from a wandering spleen.

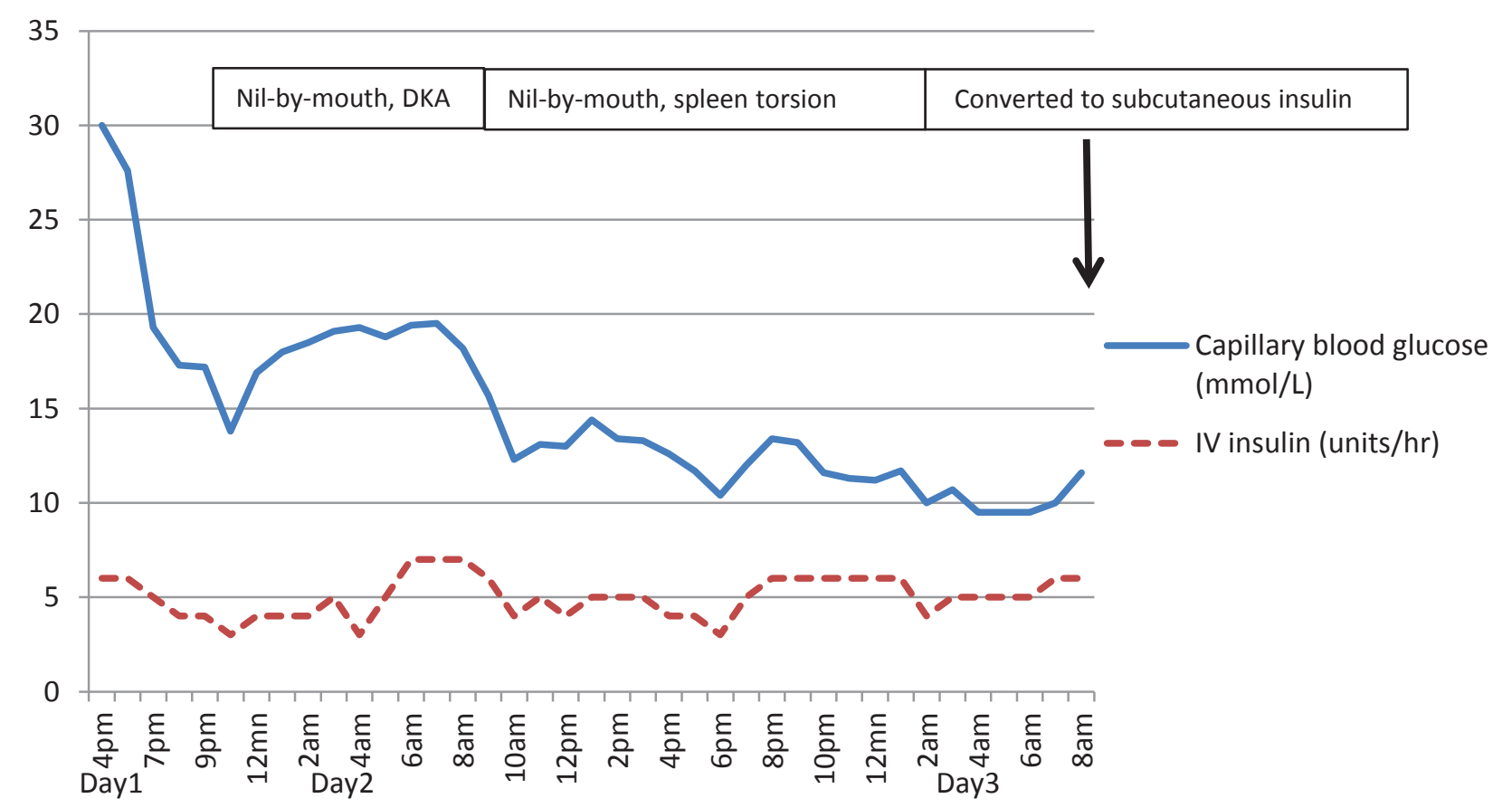

Figure 1. Capillary glucose trend with intravenous insulin therapy over $1^{\text {st }} 40$ hours.
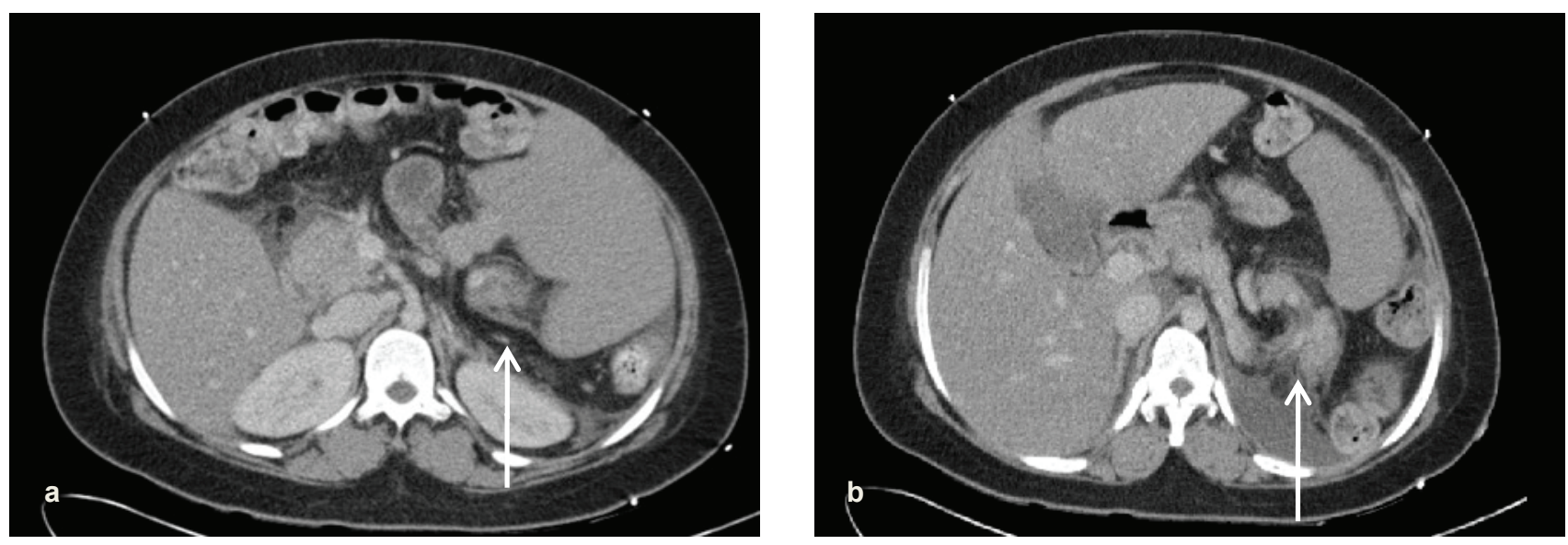

Figure 2. Torsion of patient's wandering enlarged spleen, with "whirling' of spleen (white arrow in picture a) and involving the pancreatic tail (white arrow in picture b). 
A wandering spleen is a rare disorder with the incidence in a general population of less than $0.2 \% .{ }^{13}$ A wandering spleen can be congenital or acquired. The congenital cause is due to absence or weakness of ligaments holding the spleen. In these cases, the spleen is held by a vascular pedicle instead of ligaments. The blood vessels in the vascular pedicle can be blocked leading to ischaemia and infarction of the spleen. Acquired wandering spleen is due to weakness of the ligaments such as in pregnancy ${ }^{14}$ and abdominal wall laxity. Usually, this is found in males under 10 years old, or females at 20-40 years old when they present with splenic torsion.6,15 A wandering spleen presents in a variety of manner from asymptomatic to an acute abdomen. ${ }^{16}$ The complications associated with a wandering spleen include gastric obstruction, spleen infarction and recurrent pancreatitis. ${ }^{17} \mathrm{~A}$ wandering spleen is associated with splenomegaly. The classic "whirl" appearance represents the twisted splenic pedicle signifying a torted spleen. ${ }^{18}$ In this case, the pancreatic tail was involved because it was entrapped in the twisted splenorenal ligament during spleen torsion. This led to acute pancreatitis possibly because of pancreatic ischaemia or folding of the main pancreatic duct. ${ }^{19,20}$

Despite increased risk of hepatosplenomegaly in PraderWilli syndrome, a wandering spleen was not previously reported. It is not clear in this case whether the wandering spleen was congenital or acquired. Our patient with PWS has ligament laxity ${ }^{21}$ which may have contributed to her wandering spleen. Splenectomy is performed in most cases especially in the setting of torsion, infarction or acute abdomen. ${ }^{13,16}$ Splenopexy can be considered if there is no evidence of infarction, thrombosis or hypersplenism. ${ }^{16}$

Hyperamylasemia is also seen commonly in DKA but is nonspecific. ${ }^{22}$ Lipase levels may be more helpful. A retrospective review showed that patients with DKA and abdominal pain with lipase levels $>400$ units were at increased risk of underlying abdominal pathology. ${ }^{23}$ In this case, her amylase was raised at $>600$ units. Therefore, significantly raised levels of lipase and amylase are helpful pointers to do further abdominal imaging in a patient with DKA.

\section{Conclusion}

Splenic torsion should be considered as a differential diagnosis in a patient with PWS presenting with abdominal pain. In this case, the torsion of the wandering spleen and accompanying pancreatitis precipitated the DKA.

\section{Ethical Consideration}

Written informed consent was obtained from the parent of the patient for publication of this case report and accompanying images.

\section{Statement of Authorship}

All authors have given approval to the final version submitted.

\section{Author Disclosure}

All the authors declared no conflicts of interest.

\section{Funding Source}

None.

\section{References}

1. Deal CL, Tony M, Höybye C, Allen DB, Tauber M, Christiansen JS. Growth Hormone Research Society workshop summary: Consensus guidelines for recombinant human growth hormone therapy in Prader-Willi syndrome. J Clin Endocrinol Metab. 2013;98(6):E1072-87. http://dx.doi.org/10.1210/jc.2012-3888.

2. Emerick JE, Vogt KS. Endocrine manifestations and management of Prader-Willi syndrome. Intl J Pediatr Endocrinol. 2013;2013(1):14. http://dx.doi.org/10.1186/1687-9856-2013-14.

3. Butler JV, Whittington JE, Holland AJ, Boer H, Clarke D, Webb T. Prevalence of, and risk factors for, physical ill-health in people with Prader-Willi syndrome: A population-based study. Dev Med Child Neurol. 2002;44(4):248-55.

4. Matz R. Hypothermia in diabetic acidosis. Hormones. 1972;3(1):3641. http://dx.doi.org/10.1159/000178256.

5. Schnier LM. A case of splenic torsion with progressive anemia and thrombocytopenia. Can Vet J. 2010;51(5):527-9.

6. Lam Y, Yuen KKY, Chong LC. Acute torsion of a wandering spleen. Hong Kong Med J. 2012;18(2):160-2.

7. Greenswag LR. Adults with Prader-Willi syndrome: A survey of 232 cases. Dev Med Child Neurol. 1987;29(2):145-52. http://dx.doi.org/10.1111/j.1469-8749.1987.tb02129.x.

8. Kitabchi AE, Umpierrez GE, Miles JM, Fisher JN. Hyperglycemic crises in adult patients with diabetes. Diabetes Care. 2009;32(7):133543. http://dx.doi.org/10.2337/dc09-9032.

9. Tan H, Zhou Y, Yu Y. Characteristics of diabetic ketoacidosis in Chinese adults and adolescents - A teaching hospital-based analysis. Diabetes Res Clin Pract. 2012;97(2):306-12. http://dx.doi.org/ 10.1016/j.diabres.2012.05.004.

10. Yan SH, Sheu WHH, Song YM, Tseng LN. The occurrence of diabetic ketoacidosis in adults. Intern Med. 2000;39(1):10-4. http://dx.doi.org/10.2169/internalmedicine.39.10.

11. Yigit S, Estrada E, Bucci K, Hyams J, Rosengren S. Diabetic ketoacidosis secondary to growth hormone treatment in a boy with Prader-Willi syndrome and steatohepatitis. J Pediatr Endocrinol Metab. 2004;17(3):361-4. http://dx.doi.org/10.1515/JPEM.200.17.3.361.

12. Prato SD. Role of glucotoxicity and lipotoxicity in the pathophysiology of type 2 diabetes mellitus and emerging treatment strategies. Diabet Med. 2009;26(12):1185-92. http://dx.doi.org/ 10.1111/j.1464-5491.2009.02847.x.

13. Mackintosh CE. Re: Wandering spleen: Case report and literature review. Satyadas et al. J R Coll Edinb. 2002;47:512-514. Surgeon. 2003;1(2):123.

14. Denehy T, McGrath EW, Breen JL. Splenic torsion and rupture in pregnancy. Obstet Gynecol Surv. 1988;43(3):123-31.

15. Leci-Tahiri L, Tahiri A, Bajrami R, Maxhuni M. Acute abdomen due to torsion of the wandering spleen in a patient with Marfan Syndrome. World J Emerg Surg. 2013;8(1):30. http://dx.doi.org/ 10.1186/1749-7922-8-30.

16. Buehner M, Baker MS. The wandering spleen. Surg Gynecol Obstet. 1992;175(4):373-87.

17. Karmazyn B, Steinberg R, Gayer G, Grozovski S, Freud E, Kornreich L. Wandering spleen - the challenge of ultrasound diagnosis: Report of 7 cases. J Clin Ultrasound. 2005;33(9):433-8. http://dx.doi. org/10.1002/jcu.20165.

18. Ely AB, Zissin R, Copel L, Vasserman M, Hertz M, Gottlieb P et al. The wandering spleen: CT findings and possible pitfalls in diagnosis. Clin Radiol. 2006;61(11):954-8. http://dx.doi.org/10.1016/j.crad. 2006.06.007.

19. Aswani Y, Anandpara KM, Hira P. Wandering spleen with torsion causing pancreatic volvulus and associated intrathoracic gastric volvulus: An unusual triad and cause of acute abdominal pain. JOP. 2015;16(1):78-80. http://dx.doi.org/ 10.6092/1590-8577/2905.

20. Gorsi U, Bhatia A, Gupta R, Bharathi S, Khandelwal N. Pancreatic volvulus with wandering spleen and gastric volvulus: an unusual triad for acute abdomen in a surgical emergency. Saudi J Gastroenterol. 2014;20(3):195-8. 
21. Cimolin V, Galli M, Grugni G, Vismara L, Albertini G, Rigoldi C et al. Gait patterns in Prader-Willi and Down syndrome patients. J Neuroeng Rehabil. 2010;7:28. http://dx.doi.org/10.1186/1743-0003-7-28.

22. Yadav D, Nair S, Norkus EP, Pitchumoni CS. Nonspecific hyperamylasemia and hyperlipasemia in diabetic ketoacidosis: Incidence and correlation with biochemical abnormalities. Am J Gastroenterol. 2000;95(11):3123-8. http://dx.doi.org/10.1111/j.15720241.2000.03279.x.
23. Pant N, Kadaria D, Murillo LC, Yataco JC, Headley AS, Freire AX Abdominal pathology in patients with diabetes ketoacidosis. Am J Med Sci. 2012;344(5):341-4. http://dx.doi.org/10.1097/MAJ. 0b013e3182648740.

Authors are required to accomplish, sign and submit scanned copies of the JAFES Author Form consisting of: (1) the Authorship Certification that the manuscript has been read and approved by all authors, and that the requirements for authorship have been met by each author, (2) the Author Declaration that the article represents original material that is not being considered for publication or has not been published or accepted for publication elsewhere, (3) the Statement of Copyright Transfer[accepted manuscripts become the permanent property of the JAFES and are licensed with an Attribution-Share Alike-Non-Commercial Creative Commons License. Articles may be shared and adapted for non-commercial purposes as long as they are properly cited], (4) the Statement of Disclosure that there are no financial or other relationships that might lead to a conflict of interest. For Original Articles involving human participants, authors are required to submit a scanned copy of the Ethics Review Approval of their research. For manuscripts reporting data from studies involving animals, authors are required to submit a scanned copy of the Institutional Animal Care and Use Committee approval. For Case Reports or Series, and Images in Endocrinology, consent forms, are required for the publication of information about patients; otherwise, authors declared that all means have been exhausted for securing such consent. Articles and any other material published in the JAFES represent the work of the author(s) and should not be construed to reflect the opinions of the Editors or the Publisher.

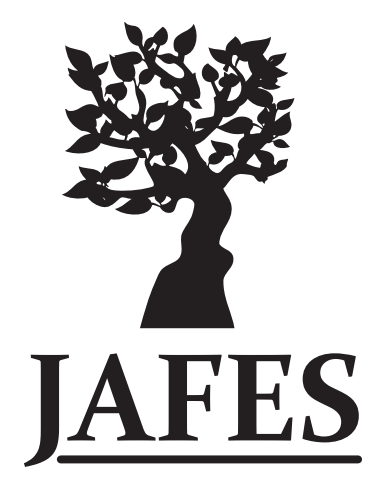

\section{A new venue for publishing your original articles. Visit www.ASEAN-endocrinejournal.org for Instructions to Authors.}

